\title{
El sentido de De los nombres de Cristo de fray Luis de León (y una posible fuente)
}

\author{
Michael MCGAHA \\ Pomona College, Claremont, California
}

En una clase sobre la mística española (musulmana, judía y cristiana) que di el año pasado, les asigné a mis estudiantes la lectura de De los nombres de Cristo. Esos mismos estudiantes, que habían leído con deleite algunos textos sumamente difíciles como los de Ibn 'Arabī y el Séfer ha-Zóhar y más tarde los escritos de Santa Teresa y de San Juan de la Cruz, sin embargo -pese a sus esfuerzos por comprender y estimar De los nombres de Cristoacabaron odiándolo. A pesar de su belleza literaria y del interés filosófico de algunos pasajes, el libro les parecía absurdo y pesado. Lo calificaban, como antes lo había hecho Azorín, de (Martínez Ruiz pág. 184)

una serie de disertaciones, a ratos difusas, sobre materias que hoy no admiten disertación. En conjunto, para los hombres del presente, la obra carece de sentido y de idealidad ... pero el hecho es que hay algo -mucho- de cansado y de prolijo en este libro.

Entonces me di cuenta de que, de todos los textos clásicos del Siglo de Oro, es posible que De los nombres de Cristo sea el de más difícil acceso para los lectores de hoy; y me pregunté el porqué. Creo haber encontrado una explicación parcial en el siguiente comentario de Miguel Durán (pág. 125):

Los más inteligentes entre [los críticos católicos de Luis de León], como Alain Guy, son muy elocuentes al explicar la sección de De los nombres de Cristo en que se comentan los temas 
filosóficos generales, pero no dicen nada sobre las secciones principales en que León explica el sentido de cada uno de los nombres de Cristo. Quizás esto se deba al hecho de que el lector moderno es consciente de que la mayor parte de estos nombres, pertenecientes al Antiguo Testamento, parecen tener un contacto bastante leve con Cristo. La mayor parte de los epítetos que se aplican a Dios, y que León explica, pertenece, entonces, al Dios del Antiguo Testamento, al Padre de Cristo, no al Hijo. Únicamente cuando se interpreta cada pasaje importante del Antiguo Testamento como una profecía y además relacionada con el Nuevo Testamento, se puede llevar a cabo esta transferencia de nombres del Padre al Hijo. La postura de León era aceptable durante la Edad Media y el Renacimiento, cuando los estudios bíblicos todavía estaban en una etapa primitiva. Pero no es aceptable hoy en día ${ }^{1}$.

Concluye Durán que «León era mejor pensador y metafísico que estudioso de la Biblia» (pág. 125).

Muchos años antes, Karl Vossler había expresado análoga opinión (pág. 56):

Al lado de mucha poesía de la naturaleza terrena, de la grandeza divina y del alma humana, hay también fragmentos algo secos en esa magnífica obra que fue ideada y empezada en la prisión y terminada después de haber recuperado Fray Luis la libertad. Por ello, el lector actual ha de hacer ante ella inevitables reservas, sobre todo en lo que se refiere a la cuestión de si realmente mediante algunos nombres con los que es designado Jesucristo se puede llegar a adquirir un conocimiento profundo de su ser y esencia. La mayor parte de esos nombres pueden sólo comprenderse metafóricamente o por vía de comparación: pimpollo, cara o faces, camino, pastor, monte, padre del siglo futuro, brazo de Dios, rey de Dios, Príncipe de paz, esposo, hijo, cordero, amado. Únicamente al final del primer diálogo se intenta la explicación del nombre de Jesús y, precisamente, esta explicación nos parece artificiosa. Estamos acostumbrados a distinguir rigurosamente entre cosas y palabras y entre el ser sustancial y permanente de las cosas y sus denominaciones fluctuantes.

Vossler criticó algunas de las interpretaciones de fray Luis como ejemplos de «devoción pueril», diciendo que «ciertos pasajes en

\footnotetext{
1 He traducido este pasaje del original inglés.
} 
estos diálogos pueden parecer al lector moderno demasiado medievales», pero que tal medievalismo era de esperar en un escritor que, al fin y al cabo, era no sólo monje sino un «español auténtico» (pág. 58).

Creo que Vossler y Durán han logrado explicar por qué De los nombres de Cristo desconcierta a tantos lectores de hoy. Sin embargo, sus explicaciones no dejan de hacerle gran injusticia a fray Luis. Fray Luis de León fue de hecho un auténtico pionero en los estudios bíblicos, muy por delante de sus contemporáneos en su acercamiento crítico al texto bíblico; por lo general, sus interpretaciones bíblicas no son ni «pueriles» ni «medievales». Tenía poca paciencia frente a las interpretaciones esotéricas de las Escrituras. Como buen humanista, filólogo y hebraísta, le interesaba sobre todo establecer un texto fidedigno y elucidar su sentido literal.

La publicación en 1957 del Tractatus de sensibus sacrae Scripturae (García de la Fuente), una serie de conferencias que fray Luis dio hacia 1568-1569 2 , ha contribuido a aclarar sus ideas sobre la relación entre el sentido literal de la Biblia y el alegórico. Como ha señalado Colin Thompson (págs. 99-100):

En [las] dos últimas secciones [del tratado] se enfrenta al problema de las limitaciones y los peligros que toda alegoría conlleva, así como al del establecimiento de la verdad dogmática a partir únicamente del sentido literal. La excesiva confianza en una interpretación alegórica podría desviarnos fácilmente de la verdad que ésta revela, consiguiendo que la lectura de las Escrituras adquiera el sentido que uno quiera darle ... La alegoría podía convertir textos de fácil comprensión en oscuros y difíciles, así como también podía llegar a desafiar la base de las afirmaciones doctrinales de la Biblia.

Sin embargo, fray Luis no condena del todo el uso de la interpretación alegórica. En palabras de Thompson (págs. 100-101):

2 El P. García de la Fuente creía que esas conferencias se dictaron en 1581, fecha que aparece en el manuscrito único. Ángel Alcalá («De la datación» pág. 866) ha demostrado que esa fecha corresponde sólo a la copia hecha por un anónimo discípulo de fray Luis y que las conferencias datan de 1568-1569. Durante el proceso de fray Luis un estudiante llamado Martín Otín se refiere a «los scriptos de el Maestro fray Luis De sensibus Scripturae», como lo hace también el mismo fray Luis en un documento del 4 de mayo de 1575. 
La alegoría puede ciertamente utilizarse con el fin de explicar el Pentateuco, especialmente el libro del Levítico, con sus ritos y ceremonias, así como los demás libros históricos del Antiguo Testamento. Hace caso omiso del corpus de literatura profética, aunque reitera su advertencia: «Iterum autem admoneo ut non quavis occasione, sumpta confugiamos ad allegorias, sed assuescamus eis uti raro et maturo consilio, et fugiamus imperitos quosdam homines, qui quovis testimonio proposito statim suam adiungunt interpretationem allegoricam», «aconsejo no recurrir a las alegorías en todo momento, sino acostumbrarse a utilizarlas en menor medida y con madura reflexión, y evitar a ciertos hombres ignorantes que enseguida dan interpretación a cualquier cosa que el texto tenga como propósito ...» «Solus sensus litteralis est efficax ad probanda et stabilienda dogmata fidei et ad destruendas haereses», «Sólo el sentido literal es capaz de probar y establecer los dogmas de la fe, así como de destruir la herejía», continúa Fray Luis.

Es especialmente interesante el hecho de que en el Tractatus fray Luis no mencione los libros proféticos como textos que se prestan a la interpretación alegórica, ya que la mayor parte de los textos que él mismo interpreta de esa manera en De los nombres de Cristo vienen de los profetas.

A pesar de estar convencido de la importancia de dar prioridad al sentido literal, fray Luis sabía que el método de exégesis bíblica más aceptado en la España de la Contrarreforma y el que se consideraba como el más ortodoxo, era el método tipológico, y por eso era sumamente circunspecto al expresar el disgusto que le inspiraba. Por ejemplo, en el Prólogo a su Exposición del Cantar de los cantares (pág. 72), escribe:

Cosa cierta y sabida es que en estos Cantares, como en persona de Salomón y de su esposa, la hija del rey de Egipto, debajo de amorosos requiebros, explica el Espíritu Santo la Encarnación de Cristo y el entrañable amor que siempre tuvo a su Iglesia, con otros misterios de gran secreto y de gran peso. En este sentido espiritual no tengo que tocar, que de él hay escritos grandes libros por personas santísimas y muy doctas que, ricas del mismo Espíritu que habló en este Libro, entendieron gran parte de su secreto, y como lo entendieron lo pusieron en sus escrituras, que están llenas de espíritu y regalo. Así que en esta parte no hay que decir, o porque está ya dicho, o porque es negocio prolijo y de gran espacio. 
Solamente trabajé en declarar la corteza de la letra, así llanamente, como si en este Libro no hubiera otro mayor secreto del que muestran aquellas palabras desnudas y, al parescer, dichas y respondidas entre Salomón y su Esposa, que será solamente declarar el sonido de ellas, y aquello en que está la fuerza de la comparación y del requiebro; que, aunque es trabajo de menos quilates que el primero, no por eso carece de grandes dificultades, como veremos.

Fray Luis era igualmente reacio al método judío de interpretación llamado guematria, basado en el valor numérico de las letras de cada palabra. En su comentario al nombre «Jesús» en De los nombres de Cristo (pág. 623), escribe:

Y no diré del número de las letras que contiene este nombre, ni de la propriedad de cada una dellas por sí, ni de la significación singular de cada una, ni de lo que vale en razón de aritmética, ni del número que resulta de todas, ni del poder ni de la fuerça que tiene este número, que son cosas que las consideran algunos y sacan mysterios dellas, que yo no condeno; mas déxolas, porque muchos las dizen, y porque son cosas menudas y que se pintan mejor que se dizen.

Véase que en los dos casos pone la misma excusa: no se ve obligado a practicar este tipo de interpretación, porque otros ya lo han hecho muy bien. En su manual para las mujeres casadas, $L a$ perfecta casada, basado en el último capítulo del libro de Proverbios, también prescinde de interpretaciones alegóricas, aunque el tema del libro parece reclamarlas.

Finalmente, en su obra más extensa en prosa castellana, la Exposición del libro de Job, escrita a lo largo de veinte años y que no terminó hasta unos meses antes de su muerte, aunque a veces relaciona pasajes en el libro de $J o b$ con los sufrimientos y persecuciones que él mismo padeció, de nuevo se limita a una traducción literal y a un comentario sobre el texto hebreo. De los nombres de Cristo es, por consiguiente, el único de sus comentarios bíblicos en castellano en el que fray Luis se valió de las interpretaciones tipológicas o alegóricas, un tipo de exégesis que parece haber desdeñado, o con el que por lo menos se sentía personalmente incómodo. Además, muchas de esas interpretaciones son en efecto pueriles, rebuscadas y absurdas. ¿Cómo puede explicarse esto?

En 1569 la Inquisición había nombrado a fray Luis, junto con otros cinco profesores salmantinos (Gaspar de Grajal, Martínez 
de Cantalapiedra, Juan Gallo, León de Castro y Francisco Sancho), para formar una comisión encargada de censurar la edición de la Biblia hebrea de Robert Éstienne (París 1545) con comentarios de François Vatable, profesor de hebreo en el Colegio Real de París, como requisito previo para la reedición del libro en Salamanca. Cada miembro escogió una parte de la Biblia para examinar y luego comunicar su parecer a la comisión en pleno. León de Castro, antiguo profesor de gramática y al parecer el miembro menos cualificado del equipo, escogió el libro de los Salmos.

Parece que las primeras disputas serias surgieron cuando Castro rechazó vehementemente el comentario de Vatable sobre los Sal$m o s$, diciendo que debía ser judío «porque declara los dichos lugares como judios» (Proceso pág. 16). Castro insistió en que todos los salmos se referían literalmente a la persona de Cristo. Fray Luis contestó razonablemente que algunos se referían a Cristo, pero otros se referían sólo a David; y aun otros presentaban a David como figura de Cristo. El contenido de algunos era meramente doctrinal y no se refería ni a David ni a Cristo (Proceso págs. 224-225).

Los profesores Grajal y Martínez se pusieron del lado de fray Luis. León de Castro recordaría más tarde (Proceso págs. 7-8) que

en disputas de lugares de profetas que los evangelistas y el mismo Dios declaran en los evangelios a buelto [fray Luis] con gran porfia que aunque sea ansi verdadera aquella ynterpretacion que tambien puede ser verdadera la de los judios y que lo uno y lo otro pudo significar el profeta. Y si eso es ansi que la profeçia pudo significar lo uno y lo otro, y lo que dize el apostol y lo que dize el judio, paresçele a este declarante que no podian concluir nada ni probar nada los apostoles con las profescias que citavan, porque responderia el judio, tan bien querra dezir esta profecia esto como esotro, y no me concluys.

Dijo también que fray Luis, Grajal y Martínez «tienen poco respeto a los santos Padres sino a estas ynterpretaciones de rabíes» (Proceso pág. 8).

La discusión no tardó en volverse agria y fray Luis le dijo a Castro: «no teneis aqui la autoridad mas de la que aqui os quisieramos dar», y amenazó con hacer quemar un libro que Castro estaba publicando sobre Isaías; a lo que Castro contestó indigna- 
do: «que con la graçia de Dios ni él ni su libro no prenderia fuego ni podia, que primero prenderia en sus orejas y linaje» (Proceso pág. 17), referencia insultante a la bien conocida ascendencia judía de fray Luis.

Después de muchas discusiones ásperas, el comité terminó su tarea y la Biblia fue aprobada para la publicación con algunas censuras y revisiones. No obstante, fray Luis cumplió su amenaza, denunciando el libro de Castro a la Inquisición, que secuestró la edición y prohibió que se vendiera; por lo tanto, Castro no pudo recuperar los gastos de la publicación, que habían corrido por su cuenta ${ }^{3}$.

Enfurecido, Castro se quejó al enemigo más enconado de fray Luis en la Universidad, el dominico Bartolomé de Medina, y los dos hombres comenzaron a conspirar para derribar la brillante carrera de fray Luis hasta ese momento. El 17 de diciembre de 1571 fray Bartolomé de Medina denunció a los profesores Grajal y Martínez, junto con fray Luis, a la Inquisición, aseverando que: (1) fray Luis había traducido el Cantar de los cantares al español; (2) fray Luis, junto con los profesores Grajal y Martínez «en sus paresçeres y disputas quitan alguna autoridad a la edicion vulgata diziendo que se puede hazer otra mejor y que tiene falsedades» (Proceso pág. 6); (3) Grajal, Martínez y fray Luis eran «afectos siempre a novedades»; y (4) «quando se ofrescen disputas por la mayor parte los dichos tres maestros prefieren a Vatablo, Pagnino y sus judios, a la traslacion vulgata y al sentido de los santos, lo qual a este declarante ofendia mucho" (Proceso pág. 16). Por el término «el sentido de los Santos» se entiende la interpretación alegórica, mientras que «Vatablo, Pagnino y sus judíos» representan el sentido literal.

Según Ciriaco Morón Arroyo (pág. 301):

los términos de la contienda que le llevan a la cárcel [a fray Luis] son, pues, el concepto de sentido literal y de alegoría. Los sabios alegorines ${ }^{4}$ se abroquelaban en la alegoría porque no sabían hebreo y no podían percibir el sentido original del texto.

Fray Luis se dio cuenta de que la investigación comenzaba a volverse peligrosa, y el 6 de marzo de 1572 sometió una «Confe-

\footnotetext{
3 Por fin logró publicarlo en 1570.

4 Insulto dirigido por Grajal a León de Castro.
} 
sión» a los inquisidores. Admitió haber traducido y comentado el Cantar de los cantares, pero dijo que lo había hecho a instancias de una monja y sólo para su uso personal. Más tarde, otros lo habían copiado y circulado sin que él lo supiera ni consintiera. Dijo que tenía muchos enemigos personales en la Universidad de Salamanca, entre los cuales figuraban algunos frailes dominicos y jerónimos, León de Castro y los profesores Rodríguez y Muñoz, y rogó a los inquisidores que no les consultaran en su proceso.

Junto con la confesión, sometió una lista cuidadosamente matizada de unas veintiuna proposiciones en latín, que abarcaba sus creencias esenciales sobre las Escrituras. Estas proposiciones son en su mayoría una contestación a los argumentos proferidos por León de Castro. Ciriaco Morón Arroyo (pág. 301) ha resumido esos argumentos de la siguiente manera:

Los Setenta, sostiene León de Castro, fueron inspirados por Dios en su traducción. Es verdad que algunas veces no son fieles al texto hebreo que poseemos hoy, pero ellos fueron los citados por los Apóstoles y por los Santos Padres; debemos, pues, pensar que tuvieron un texto hebreo distinto del conservado y esta traducción que responde al texto perdido tiene mayor autoridad que la actual Biblia hebrea.

Aducía fray Luis que, si el texto hebreo de la Biblia que ahora poseemos corresponde a la versión original, es de la autoridad más alta y santa, ya que contiene las propias palabras dictadas por el Espíritu Santo; por eso, hay que corregir todas las demás versiones a la luz de la Biblia hebrea y hay que decidir todas las cuestiones de fe basándose en ese texto. Más tarde afirmó que en su opinión los judíos no habían falsificado jamás el texto bíblico. Arguyó que la versión original de los Setenta probablemente había contenido sólo los cinco libros de Moisés y que los traductores no gozaban de la inspiración divina sino que traducían «ut homines docti solent, suo marte» ('como suelen hacer los hombres sabios, con su propio entendimiento') (Proceso pág. 621). A continuación ofreció una serie de ejemplos de casos en que la Vulgata había traducido incorrectamente los originales hebreo y griego, demostrando así que los traductores de la Vulgata tampoco fueron divinamente inspirados. Concluyó con una cita del comentario de Alonso de Vega sobre los decretos del Concilio de Trento (Proceso pág. 625): 
Approbavit concilium vulgatam editionem, sed non eam, tamquam de coelo elapsam adorari voluit. Sciebat enim interpretem illius (quisquis ille fuit) non fuisse prophetam. Ac proinde neque cohibuit, neque voluit cohibere studiosorum industriam qui aliquando docent alique potuisse aliquando melius verti et se uno eodemque verbo plus esse sensus vel certe alios commodiores quam ex vulgata possunt ${ }^{5}$.

Según fray Luis, cuando el Concilio declaró que la Vulgata era «auténtica», esto sólo quería decir que no contenía ningún error del que se podría deducir un dogma pernicioso a la fe ni a la moral.

El 27 de marzo de 1572 fray Luis fue detenido y sus bienes fueron secuestrados. Iba a estar preso más de cuatro años -hasta el 11 de diciembre de 1576- en la cárcel de la Inquisición en Valladolid, donde sufriría privaciones indecibles.

Muchos testigos dieron testimonio de su falta de respeto por la Vulgata y su preferencia por la Biblia hebrea. El notario de la Inquisición para las diócesis de Cuenca y Sigüenza sometió transcripciones parciales de los procesos de varios antepasados de fray Luis, incluso de su bisabuela paterna, Leonor de Villanueva, a quien en 1512 se había hallado culpable de judaizar y fue condenada a cadena perpetua con confiscación de sus bienes. Lo mismo le había pasado a su hermana, Juana Rodríguez, mujer de Álvar Fernández de León. También los abuelos de las dos mujeres, Fernán Sánchez de Villanueva y Elvira Sánchez, habían sido condenados post mortem por judaizantes y sus restos se habían desenterrado y quemado públicamente. En 1548, cuando fray Luis tenía veintiún años, la Inquisición había mandado que se exhibieran los sambenitos conmemorando la condenación de sus antepasados en la iglesia principal de Belmonte, su lugar natal, aunque la familia había pedido que se colgaran en la iglesia de Quintanar, donde habían ocurrido sus «crímenes».

Durante el proceso de fray Luis se hizo mucho hincapié en su ascendencia judía, lo cual naturalmente reforzaba las sospechas

5 'El Concilio aprobó la edición Vulgata, pero no quería que se la adorara como si hubiera caído del cielo. Sabía que el traductor, quienquiera que fuera, no era profeta; por eso no disuadió ni quería disuadir a los estudiosos de sus esfuerzos por demostrar que algunos pasajes podrían ser mejor traducidos, ni tampoco decir que una sola palabra no podía tener más de un sentido, o aun en ciertos casos, una mejor traducción que la que da la Vulgata'. 
que de él se tenían. El inquisidor Diego González, al votar por el encarcelamiento de Gaspar de Grajal y de fray Luis, escribió (Proceso pág. 33, n. 45) que

por ser Grajal y fray Luis notorios conversos, pienso que no deven querer mas de oscurecer nuestra fee Catholica e bolberse a su ley, y por esto es mi boto y parecer que el dicho frai Luis de Leon sea preso y traido a las cárceles del santo officio para que con el fiscal siga su causa.

Algunos testigos afirmaron que había expresado dudas sobre la venida del Mesías, implicando así que era un criptojudío (Proceso pág. 234). Otros dijeron que a sabiendas había poseído un libro herético por «un italiano abilissimo», que Benito Arias Montano le había regalado y que según fray Luis, «le avia dado luz y quitado muchas marañas» (Proceso pág. 147). Muchos se decían escandalizados por su tratamiento del Cantar de los cantares como un intercambio de poesías eróticas entre el rey Salomón y su esposa.

Ángel Alcalá ha sostenido que la mayor parte de esas denuncias -que la traducción de los Setenta no gozaba de inspiración divina, que algunos pasajes de la Vulgata estaban mal traducidos, etc.- no tenían importancia. Según Alcalá («Peculiaridad» pág. 78), la cuestión palpitante en el proceso de fray Luis era su insistencia en que había que conceder prioridad al sentido literal del texto de la Biblia hebrea y desconfiar de las interpretaciones alegóricas:

Lo que escandalizó a León de Castro en las reuniones y al escuchar la exposición del De sensibus por fray Luis, y lo que se discutió en largas secuencias del proceso fue que, para la mente de un escolástico tradicional, esa doctrina invita a tal laxitud hermenéutica que desguarniza las murallas textuales tras las que tradicionalmente se ha embravecido la actividad teológica cristiana de talante apologético, es decir, relativamente realista.

Fray Luis comenzó a escribir De los nombres de Cristo en la cárcel ${ }^{6}$. A mi parecer, el libro es más que nada su intento de de

${ }^{6}$ Escribe en la Dedicatoria (págs. 145-146): «... aunque me conozco por el menor de todos los que en esto que digo pueden servir a la Iglesia, siempre la desseé servir en ello como pudiesse; y por mi poca salud y muchas occupaciones no lo he hecho hasta agora. Mas ya que la vida passada, occupada y trabajosa, me fue estorvo para que no pusiesse este mi desseo y juyzio en execución, no me parece que devo perder la occasión deste ocio en que la injuria y mala voluntad de algunas personas me han puesto; porque, aunque son muchos los trabajos que me tienen cercado, pero el favor largo del cielo, que Dios, padre verdadero de los 
fenderse contra las acusaciones de sus enemigos. Le hacía falta mostrar que su conocimiento del hebreo y de la Biblia hebrea, lejos de conducirle a «herejías» judías, en realidad le servía para apoyar la doctrina cristiana. Y más aún, que el texto hebreo de la Biblia es a veces más claro en sus referencias tipológicas a Jesús que la Vulgata. Importaba señalar que conocía y sentía el más profundo respeto por las interpretaciones bíblicas de los Padres de la Iglesia («el sentido de los santos»).

Como ha señalado Jesús María Nieto Ibáñez (pág. 556):

Son muchos los pasajes de los Padres, tanto griegos como latinos, que surgen en la lectura de [De los nombres de Cristo]: Cirilio, Orígenes, Ignacio de Antioquía, Gregorio de Nacianzo, Pseudo-Dionisio Areopagita, el papa san León, en una ocasión cada uno de ellos, san Jerónimo, san Juan Crisóstomo, Teodoreto, Gregorio de Nisa, Basilio, san Bernardo, en dos ocasiones, san Agustín, cuatro veces, y san Macario, cinco.

Es curioso que sea San Macario el padre más frecuentemente citado por fray Luis. Sus obras se habían publicado por primera vez en Europa en 1559, tanto el original griego como una traducción latina. Según Nieto Ibáñez, San Macario pone énfasis en «la oración interna frente a las ceremonias y actos externos» (pág. 559), como pasa también con fray Luis, así como con tantos otros escritores conversos y también con los reformadores protestantes.

Me parece especialmente interesante el siguiente pasaje del comentario de fray Luis sobre el nombre "Amado" (pág. 606), traducido de la Homilía IX de san Macario:

... no se permite que ninguno halle al amor celestial del espíritu si no se enagena de todo lo que este siglo contiene y se da a sí mismo a sola la inquisición del amor de Jesús, libertando su alma de toda solicitud terrenal para que pueda ocuparse solamente en un fin, por medio del cumplimiento de todo cuanto Dios manda.

agraviados, sin merecerlo me da, y el testimonio de la consciencia en medio de todos ellos, han serenado mi ánima con tanta paz, que no sólo en la enmienda de mis costumbres, sino también en el negocio y conocimiento de la verdad, veo agora y puedo hazer lo que antes no hazía. Y hame convertido este trabajo el Señor en mi luz y salud, y con las manos de los que me pretendían dañar ha sacado mi bien. A cuya excellente y divina merced en alguna manero no respondería yo con el agradescimiento devido, si agora que puedo, en la forma que puedo y según la flaqueza de $\mathrm{mi}$ ingenio $\mathrm{y}$ mis fuerças, no pusiesse cuydado en aquesto que, a lo que yo juzgo, es tan necessario para el bien de sus fieles». 
No creo que sea casual el uso de la palabra «inquisición»en esta frase. Sugiere que la única inquisición digna de un cristiano es la del amor de Jesús, implicando que la Inquisición (con mayúscula) es una «solicitud terrenal» que impide al cristiano alcanzar el amor divino.

Por fin, fray Luis tenía que demostrar que no era nada reacio a las interpretaciones alegóricas, sino que era capaz de sobrepasar aun a los tipólogos más celosos.

Según creo, este cambio radical en el método hermenéutico practicado por fray Luis antes y después de De los nombres de Cristo era totalmente insincero. Fray Luis estaba convencido de que «la origen y causa total desta denunciacion que se hizo contra my, no fue el zelo de fe, ny de verdad, sino pasion y odio, y deseo de destruirme con mentiras y calumnias» (Proceso pág. 327); y en su desesperación, parece haber decidido volver contra sus enemigos sus propias armas («mentiras»).

Como ha señalado Ángel Alcalá, el proceso de fray Luis se alargó debido en parte a «ciertas actitudes duras, inflexibles y vengativas adoptadas por fray Luis, cuya altura moral, y hay que confesarlo con pena, no siempre estuvo al nivel de lo que de una persona abundante en humildad, paciencia y santidad se hubiera podido y debido esperar» («Peculiaridad» pág. 73).

No creo que esas actitudes hayan cambiado de manera esencial durante sus años de cárcel. Posiblemente se recrudecieran. Así como Cervantes escribió en el Quijote el último y mejor de los libros de caballerías para «derribar la máquina mal fundada destos caballerescos libros» (vol. I pág. 58), en De los nombres de Cristo quiso fray Luis acabar para siempre con el género de interpretación bíblica cultivado por los «sabios alegorines».

Muchas de sus interpretaciones de los «nombres de Cristo» en la Biblia hebrea son tan patentemente absurdas como para parecer parodias del género. Como es natural fray Luis era perfectamente consciente de esto y sabía que sus lectores más inteligentes se darían cuenta del propósito del libro ${ }^{7}$; pero también sabía que

\footnotetext{
${ }^{7}$ Asunción Rallo Gruss (pág. 454) ha calificado De los nombres de Cristo de «un adoctrinamiento especialmente escrito para iniciados, para los que comparten con el autor una preparación filológica y religiosa» y Cristóbal Cuevas ha señalado en su edición del libro (pág. 38) que «no es una obra popular, ni de divulgación, sino minoritaria, destinada tan sólo a lectores cualificados».
} 
sus enemigos eran tan ignorantes que sólo podrían tomar sus palabras al pie de la letra, ya que no sabían hebreo y eran incapaces de discrepar de sus interpretaciones. Siguiendo la pauta de León de Castro, «demostraría» que se pueden encontrar referencias a Cristo en la Biblia hebrea aun en los lugares en donde menos son de esperar.

Podría citar numerosos ejemplos, pero me limitaré a uno que me parece especialmente notable. En su comentario al nombre «Faces de Dios» (pág. 193) dice fray Luis que, cuando Dios se le apareció a Moisés en la zarza ardiente y Moisés le pidió una señal de quién era, Dios contestó:

El que seré, seré, seré ${ }^{8}$, repitiendo esta palabra de tiempo futuro tres vezes, y como diziéndoles: Yo soy el que prometí a vuestros padres venir agora para libraros de Egypto, y nascer después entre vosotros para redimiros del peccado, y tornar últimamente en la misma forma para destruyr la muerte y perficionaros del todo.

Cuando Moisés transmitiera este mensaje a los líderes de los hebreos, estos sabrían que su Dios lo había enviado. Sabemos que la venida de Cristo le había sido revelada a Abraham, porque San Juan nos dice en su evangelio (8:56): «Abraham deseó ver mi día; viole y gozóse». Por eso, el nombre tres veces repetido serviría de contraseña o de señal secreta, porque (pág. 194)

era caso secreto aquéste, y cosa que passava entre Dios y Abraham y algunos de sus successores, conviene saber, los successores principales y las cabeças de linaje, con los quales, de uno en otro y como de mano en mano, se avía comunicado este hecho y promessa de Dios.

Fray Luis no menciona de donde había sacado esta interpretación rebuscada. Juliano objeta que el verbo hebreo 'ehyé empleado en este versículo ( $E x$ 3:14), aunque gramaticalmente es un futuro, se refería en realidad al tiempo presente («soy»). Marcelo admite que de hecho San Jerónimo y antes de él los Setenta así comprendían el versículo y que tal interpretación es, por tanto,

${ }^{8}$ Lo que Dios en realidad le dijo, según la Vulgata, era: «EGO SUM QUI SUM. Ait: Sic dices filiis Israel: QUI EST, misit me ad vos» ('Yo SOY EL QUE SOY. Y dijo: Así dirás a los hijos de Israel: YO SOY [o ÉL QUE ES] me envió a vosotros'). 
admisible. Insiste, no obstante, en que «sin sacar de sus términos a aquellas palabras, sino tomándolas en su primer sentido y significación, nos declaran el mysterio que he dicho» (pág. 194). Visto de esta manera, el texto hebreo apoya mejor que la Vulgata la interpretación tipológica.

Es sumamente irónico que la fuente empleada por fray Luis para llegar a esta interpretación tipológica fuera, de hecho, uno de los principios básicos de la Cábala judía: el de la transmisión esotérica del sentido secreto del nombre de Dios. Como escribió el rabino Ezrá de Gerona en su Comentario al Cantar de los cantares (pág. 42):

Desde ese momento hasta el presente, ninguna generación en Israel ha sucedido a la anterior sin recibir las tradiciones de la sabiduría, es decir, el conocimiento del Nombre, siguiendo el orden de la transmisión de la Torá oral.

Por cierto, justo antes de morirse, cuando se le cerraban las tradiciones de la sabiduría, [Moisés] entregó esta sabiduría a Josué: «Y Josué hijo de Nun fue lleno del espíritu de sabiduría, porque Moisés había puesto las manos sobre él» (Deut 34:9); Josué, a su vez la pasó a los Ancianos. Estos eran los jefes de la generación, los guías de Israel. Rezaron por el pueblo de Israel, y el pueblo les obedecía y seguía sus órdenes: «Y sirvió Israel a Jehová todo el tiempo de Josué y todo el tiempo de los ancianos que sobrevivieron a Josué» (Jos 24:31). Los Ancianos la pasaron a los profetas, y de ellos pasó a los hombres de la Gran Asamblea, Daniel, Hananiá, Mišael y Azariá, Mardoqueo, Zerubabel y Esdrás. El último de ellos era Simón el Justo.

Como es bien sabido, muchos humanistas cristianos interpretaban los textos de la Cábala desde un punto de vista cristológico, creyendo que esos textos «antiguos» se referían de manera velada al misterio de la redención. Hoy sabemos que la mayor parte de tales textos se escribieron en España durante la Edad Media y que estaban influidos por la teología católica, lo que explica esos paralelos.

En mi opinión fray Luis veía las interpretaciones esotéricas de la Biblia que aparecen en la Cábala con la misma reserva que sentía frente a la exégesis alegórica practicada por los católicos. Natalio Fernández Marcos reconoce la «extrema sobriedad y cautela [de fray Luis] en estos temas» (pág. 136), pero, no obstante, cree en su «simpatía por la Cábala cristiana» (pág. 139), aunque 
concluye su artículo afirmando que «naturalmente fray Luis no es un cabalista» (pág. 150).

Un principio que sí compartía fray Luis con los cabalistas era que muchas palabras de la Biblia pueden encerrar más de un sentido, ya que en hebreo puede cambiar el significado de una palabra según la vocalización que lleve.

Ahora bien, la interpretación canónica del «nombre» que Dios le reveló a Moisés en los versículos citados, compartida por judíos y católicos, es que manifiesta la naturaleza de Dios como Ser puro. Fray Luis reconoce (pág. 195)

que lo demás que entienden algunos aver significado y declarado Dios de sí a Moysén en este lugar, que es su perfectión infinita, y ser él el mismo ser por essencia, notorio era, no solamente a los ángeles, pero también a los demonios; y aun a los hombres sabios y doctos es manifiesto que Dios es ser por essencia y que es ser infinito, porque es cosa que con la luz natural se conosce.

¡Un sentido tan literal que pretende ser obvio tanto para los hombres sabios y doctos como para los mismos diablos seguramente no podría ser el sentido principal querido por Dios! Reitera fray Luis que el nombre divino éhyé 'ašer 'ehyé no tiene otro sentido alegórico que el que acaba de explicar.

Fácil es imaginar la sonrisa burlona que afloraría en los labios de fray Luis al pensar en la bobería de los lectores ingenuos capaces de aceptar una interpretación tan absurda, falsificadora del claro sentido de la Escritura (jamás dijo Dios: «Seré, seré, seré») y que además contradice el mensaje más importante del pasaje para la teología escolástica.

Me parece sumamente curioso que Colin Thompson haya escrito que en el comentario a este nombre «es posible escuchar la voz de fray Luis arguyendo a favor de la comprensión de las Escrituras hebreas desde un adecuado cristocentrismo, en contraposición a las parodias exegéticas de León de Castroi (pág. 188), sin darse cuenta de que se trata de otra parodia tan absurda como las de Castro.

En su comentario al nombre «Brazo de Dios» incluye fray Luis una crítica cuidadosamente meditada de la exégesis tipológica de las profecías mesiánicas de la Biblia hebrea. Cuando Marcelo cita la famosa «Canción del siervo sufriente» (Is 53) como refiriéndose 
a Cristo, objeta Juliano: «No sé yo, Marcelo, si los hebreos nos darán que Esaías, en el lugar que el papel dize, hable de Christo» (pág. 319). Marcelo admite: «Ya sé que lo declaran de sí mismos, y de su pueblo en el estado de agora» (pág. 320). Juliano observa que los judíos desde siempre han esperado que el prometido Mesías les librara de «los enemigos de su pueblo, esto es, los enemigos visibles de los hebreos, y los que los han destruydo y puesto en captividad, como fueron los chaldeos y los griegos y los romanos, y las demás gentes sus enemigas, de las cuales esperan verse vengados por mano del Messías, que, engañados, aguardan; y le llaman Braço de Dios por razón de aquesta victoria y vengança» (págs. 320-321). Juliano arguye que no es nada sorprendente que los judíos esperen un tal Mesías, ya que las profecías cuentan del Mesías que ceñirá su espada sobre su muslo, subirá en su caballo y que sus saetas agudas acribillarán los corazones de los enemigos

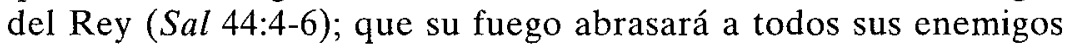
(Sal 96:1-3); cómo allegará a los fugitivos de Israel y a los esparcidos de Judá, y Edón le servirá, Moab le será sujeto y los hijos de Amón le obedecerán (Is 11:11-14); cómo perseguirá a los reyes de Moab y los aniquilará con su espada y arco (Is 15-16); cómo pisará a las naciones en su ira y su sangre salpicará sus vestidos ( $I s$ 63:3); cómo saldrá como valiente y se esforzará sobre sus enemigos (Is 42:13). A todo ello suma otras tantas profecías de los libros de Joel, Amós y Miqueas, concluyendo: «y ¿qué propheta ay que no celebre, cantando en diversos lugares, este capitán y aquesta victoria?» (pág. 323).

Marcelo contesta que los judíos hacían mal en interpretar literalmente esas profecías, que debían entenderse figuradamente refiriéndose a un triunfo del espíritu, no de las armas. Entonces Juliano razonablemente pregunta (pág. 332):

¿qué es la causa por donde Dios, ya que hazía promessa deste tan grande bien a su pueblo, se la encubrió debaxo de palabras y bienes carnales y visibles, sabiendo que para ojos tan flacos como los de aquel pueblo, era velo que los podía cegar, y sabiendo que para coraçones tan afficionados al bien de la carne, como son los de aquellos, era cevo que los avía de engañar y enredar?

¿Hacía Dios una burla cruel a su pueblo? Sin duda se habría podido expresar de una manera más comprensible. Si no quería que le entendieran, ¿por qué no se calló sin más? Como admite 
Natalio Fernández Marcos, fray Luis «no logra aclarar del todo por qué Dios les habló a los judíos de forma encubierta y como en figuras lo relativo a Cristo y sus hechos» (pág. 144).

La primera respuesta de Marcelo es que (pág. 333)

los secretos de Dios ... son abysmos profundos, por donde en ellos es ligero el difficultar, y el penetrar muy difficultoso; y el ánimo fiel y christiano más se ha de mostrar sabio en conoscer que sería poco el saber de Dios si lo comprehendiesse nuestro saber, que ingenioso en remontar difficultades sobre los que Dios haze y ordena.

Un poco más tarde, sin embargo, arguye que los pecados de los judíos «dieron a Dios causa justíssima para que tuviesse por bueno el hablarles assí figurada y rebueltamente» (pág. 336). Sabino le recuerda a Marcelo que esas profecías tuvieron lugar mucho antes de que los judíos rechazaran y crucificaran a Cristo. ¿Fueron las profecías oscuras un castigo retroactivo por un pecado que no habían cometido todavía? Si no, ¿qué pecado habían cometido los judíos para merecer un tratamiento tan cruel? Contesta Marcelo que fue el pecado de haber adorado al becerro de oro. Esta interpretación está basada en las palabras del protomártir Esteban en Hechos 7:38-53:

Este es aquel Moisés que estuvo en la congregación en el desierto con el ángel que le hablaba en el monte Sinaí, y con nuestros padres, y que recibió palabras de vida que darnos; al cual nuestros padres no quisieron obedecer, sino que le desecharon, $y$ en sus corazones se volvieron a Egipto, cuando dijeron a Aarón: Haznos dioses que vayan delante de nosotros, porque a este Moisés, que nos sacó de la tierra de Egipto, no sabemos qué le haya acontecido. Entonces hicieron un becerro, y ofrecieron sacrificio al ídolo, y en las obras de sus manos se regocijaron. Y Dios se apartó de ... vosotros que recibisteis la ley por disposición de ángeles, y no la guardasteis.

Todo este pasaje es sumamente inquietante y suscita preguntas penosas. ¿Qué clase de Dios castigaría a su pueblo mandándole tantas profecías que le indujesen en cada generación a esperar la venida de un redentor que le librara de la opresión y la persecución, cuando en realidad pretendía algo enteramente distinto? Seguramente no el Dios de amor descrito por fray Luis en otros pasajes de De los nombres de Cristo. 
¿Fue realmente tan terrible el pecado del becerro de oro como para exigir el castigo de los descendientes de los pecadores por miles de años? Parece que los rabinos del Talmud lo creían así al escribir que «no hay desgracia que Israel haya sufrido que no sea en parte una retribución por el pecado del becerro» (TB-Sanhedrin 102a).

Se me hace difícil creer que fray Luis compartiera esa opinión. Estoy convencido de que su comentario sobre el nombre «Brazo de Dios» iba orientado a demostrar los extremos absurdos hasta los que la exégesis tipológica era capaz de conducir y la arrogancia intelectual implícita en tales interpretaciones. La única reacción aceptable frente a este misterio era la inicial de Marcelo, exclamar con San Pablo (Rom 11:33): « $\mathrm{O}$ honduras de las riquezas y sabiduría y conoscimiento de Dios, quán no penetrables son sus juizios, y cuán difficultossos de rastrear sus caminos!» (pág. 333).

Ángel Alcalá es uno de los muy pocos estudiosos que se ha dado cuenta de la contradicción entre el método hermenéutico practicado por fray Luis en De los nombres de Cristo y la teoría expresada en De sensibus y en sus otros escritos sobre el asunto. Como señala Alcalá («Peculiaridad» pág. 79),

nadie ha explicado todavía cómo y por qué el mismo fray Luis que comienza su labor hermenéutica insistiendo ante todo en «la corteza de la letra» se orienta poco a poco a la elucubración alegórica y a la lectura plurivalente no literal de gran cantidad de textos bíblicos cuando le conviene para exponer con soltura y belleza una doctrina teológica preconcebida.

Y sigue: «El abismo entre la versión y comentario del Cantar, sólo manuscritos en vida, y un libro aparentemente tan extrañamente teológico como De los nombres de Cristo es patente». Según Alcalá, «es un abismo que en buena parte puede explicarse por sus reflexiones en la cárcel, sus prevenciones consiguientes y su victoria sobre ellas». Alcalá arguye ingeniosamente que el hecho de «que fray Luis, como todo teólogo, practicara ... ese tipo de uso y abuso de la alegoría bíblica, al que desde el inicio de la ruptura antijudía hubo de recurrir la intelectualidad cristiana, no implica que desconociera no ya la moderación con que debe aplicarse, sino sus esenciales limitaciones». Cree que en $D e$ los nombres de Cristo fray Luis no intenta probar nada, ni mucho menos polemizar con los judíos. Su intención es «persuadir 
al lector y hacerle gozar de una doctrina previamente admitida por él valiéndose de la armonía del pensar y la belleza del decir» (pág. 79).

Por ingenioso que sea, este argumento no me convence. A pesar de lo que dice Alcalá, no encuentro evidencia de esta «teología nueva, no probatoria, sino suasoria, comprobatoria, literaria, poética» (pág. 80) ni en La perfecta casada ni en La exposición del libro de Job, en las que, como ya mencioné, ni usa ni abusa fray Luis de las interpretaciones alegóricas como lo había hecho en $D e$ los nombres de Cristo. En esas obras vuelve a dar prioridad al sentido literal del texto hebreo de la Biblia, lo que indica que sus ideas no han cambiado.

Espero haber demostrado que la interpretación de De los nombres de Cristo, como ocurre con tantas otras obras literarias escritas en la España de la Contrarreforma, exige que se lea con cuidado entre líneas. La autocensura y la autoprotección exigían que se escribiera de una manera que se prestara a distintos niveles de interpretación. Como dije antes, los lectores ingenuos aceptarían el sentido superficial, mientras que los inteligentes verían la intención irónica de muchos pasajes.

El juego de escribir interpretaciones sumamente absurdas de las Escrituras con las que engañar y burlarse de sus ignorantes enemigos debe haberle divertido y satisfecho a fray Luis durante sus largos y penosos «ocios» en la cárcel; pero uno se pregunta cómo pudo sostener tal juego a lo largo de un libro tan extenso. La respuesta es que no lo hizo. El tema del libro es sólo aparentemente los nombres de Cristo. Fray Luis se valió de esos nombres como pretexto para tratar otras cuestiones que le interesaban en alto grado: (1) el sentido de la historia y en particular los misteriosos destinos de los pueblos judío y romano -no sólo del Imperio Romano sino de su sucesor, la Iglesia de Roma-; y (2) la justicia y el ejercicio lícito del poder.

Mientras languidecía en la cárcel fray Luis debió pasar muchas horas preguntándose por qué le había sobrevenido una desgracia tan terrible. La respuesta obvia era que esto le había acontecido por algo que estaba totalmente fuera de su control: su origen judío.

Uno de los aspectos más extraordinarios de fray Luis es su confianza en sí mismo, una confianza bordeando en hubris. A pesar del odio y el desprecio amontonados sobre los judíos y cristianos 
nuevos en la España de su época, no parece haberse avergonzado de su ascendencia judía. De otro modo, ¿cómo se podría explicar el que hiciera algo tan peligroso como dedicarse al estudio del hebreo y de la Biblia hebrea? No dejaría de ver la conexión entre su propio sufrimiento y el de sus antepasados judíos. Se consolaría en el conocimiento de que su sufrimiento, como el de los judíos, era providencial, castigo de un Dios amoroso y que al final le sería provechoso. No obstante, este hecho no podía disculpar a sus perseguidores ni a los de los judíos y cristianos nuevos; tarde o temprano a aquellos les llegaría su Día del Juicio.

Estoy convencido de que fray Luis tomó esas creencias, junto con gran parte del contenido y de la forma de De los nombres de Cristo, del libro Consolaçam ás tribulaçoens de Israel (Ferrara 1533) de Samuel Usque.

No tengo pruebas de que fray Luis conociera o no ese libro. De conocerlo, seguramente no confesaría haber leído una obra en la que un judío ofrecía una explicación providencial de los sufrimientos de su pueblo, los defendía contra la pretensión de los cristianos de haberlos suplantado en el favor divino y sugería que pronto se vería el último cumplimiento de las profecías mesiánicas de la Biblia hebrea. Sin embargo, los paralelos entre los dos libros me parecen demasiado numerosos para atribuirlos a mera coincidencia.

Ambos libros están formados por tres diálogos entre tres interlocutores en un ambiente pastoril bellamente descrito. El personaje principal de los diálogos de Usque es Ycabo (Jacob = Israel), que narra sus aflicciones a Numeo (Nahum) y Zicareo (Zacarías), "prophetas e[n] habito \& nome de pastores», quienes intentan consolarle. Usque examina el destino del pueblo judío en tres diálogos, cada uno representando una etapa distinta de la historia judía y precedido de una alegoría. Estas son: (1) desde el comienzo hasta la destrucción del Primer Templo («Vida pastoril»); (2) desde la construcción del Segundo Templo hasta su destrucción por los romanos («Caça de coelhos e lebres»); y (3) desde la destrucción del Segundo Templo hasta el presente ("Caça de çeruos»).

La tesis principal de Usque es que el pecado mayor del pueblo judío, repetido ad nauseam a lo largo de su historia, ha sido la asimilación. Cada vez que han abandonado su Torá en un deseo de emular las creencias y costumbres de los gentiles, Dios les ha castigado, haciendo que el propio pueblo al que tanto admiraban les odiara, rechazara y persiguiera. 
$\mathrm{El}$ «Diálogo II» contiene una sección de comentarios sobre «Os passos q mudarõ os q trasladarom a ley» («Los pasajes que cambiaron los que tradujeron la ley») (i.e., los Setenta). Como hemos visto una de las denuncias hechas contra fray Luis fue precisamente su falta de respeto por los Setenta.

Cada uno de los diálogos de Usque concluye con una interpretación de las profecías que pronosticaban los acontecimientos que acababa de narrar.

La alegoría que Usque emplea para representar los acontecimientos narrados en su «Diálogo II» es también muy parecida a la que fray Luis introduce al final de su comentario sobre el nombre «Jesús». El texto de Usque reza así (I, vi-vii):

A esta ora jaa hũa temperada sombra com deleitoso silençio todos aquelles alegres valles ocupaua, e sobre ligeiros ginetes ou mansas egoas, nas mãos seus esfaimados falcoẽs, as jlhargas suas çeuadeiras, nũ ayroso e verde descampado, doze ou quinze caçadores, por outra parte se descobriam, e passeando gentilmente o graçioso campo, viam de longe a real e delicada garça, ̃̃ com suas azas doçemente brãdindoas, aquelles sotys e delgados ares voando cortaua: e depois de desencaparado o grande o ligeiro Nebri dandolhe a uista da gentil aue, o atreuido falcam a ella jmpetuosamẽte saya, fazendo a ponta contraira por espaço de hũa largua legoa: e pera se milhor ensenhorear, daly pelo alto voando tornaua sobrella. E por mais que a perseguida garça se hia jnfunando em alteza jaa pela grande ponta do jmigo ficaua sopeada: e tanto, que achãdose tam junta do perigo, a sua defésa pelo derradeiro remedio corria: e virando pera riba a delicada aue seu tenrro peito co duro bico e longos pees esperando, jrosa se armaua: a hũa e outra parte sobrella o animoso falcam arremandose, e a nobre caça nam podendo resistir seu furioso jmpeto da primeira pelotada $\tilde{q}$ recebia humana e piadosamente se queixaua; e ao mais alto por se escapulir jmpinandose, e apos ella o ymigo sempre subindose e sogiguandoa, asperamente a tornaua ferir: de tal maneira aqui ligeiramente sayndo e aly manhosamente acometendo, a hia com suas longuas e agudas vnhas contino acotilando, que muitas e muitas vezes os pedaços da vençida e cansada garça vinham abayxo, e de suas pombinhas penas hũas por aquelles craros e frescos ares andauam vagando: e outras sobella verdura aqui e aly espalhandose desçiam: Algũas vezes neste passo (pera mais saborosamente, se fartar a vista) aos lasti- 
mosos gritos da ferida garça, acodia groseiro e grande milhano a socorrela, e os astuciosos caçadores, lãçãdolhe hum delles o animoso Basory, outro o forçoso Saacri, este o bicudo gerifalte, e aquelle o grãde e fermoso Tagarote, e assi jũtos animosamente os ymigos acometedo todos hus cos outros estreitamente tesçidos, vinham a fazer hua mui trauada batalha: mas ao sim as forças dos poucos enfraquecidas, jaa se rendiam aos cõtrairos, e acabando de espirar aquella fermosa aue, de seu corpo partecipauam todolos companheiros, leuãdo cadahũ parte da prea com mui grande aluoroço.

Usque explica que su garza representa la Torá, «que com suas alas, de engeniosas especulaçoẽs voando, os delgados Ares, sotils e altissimos segredos cortaua». Los cazadores eran los reyes malvados de Judá, que atacaban la Torá «com os falcoẽs de ynormes obras, ydolatrias, agouros, feitiçarias, mortes de hũs a outros» (I, xlvi). «De tal maneira, que achandose a santa ley tam junta do perigo de se perder, esforçauase a defender como os bõs Reis Assa e Yosafat ... mas apos ella o ymigo todavia sobindo e sogiguandoha, asperamẽte cõ as lõguas e agudas vnhas do pessimo Manasses e Amon (que as duas aras de ydolatria fez na casa do señor e a ymagẽ abominauel pos na santidade do tẽplo)» (I, xlvixlvii). Siguieron otros ataques -de Sisac, rey de Egipto y Senaquerib, rey de Asiria-, que culminaron en la destrucción del Templo por Nabucodonosor: «queimando \& destroindo o santo templo, \& assi os seus saçerdotes \& iustos; \& o resto de seus membros leuou a Babilonia onde antes auia os outros deixado» (I, xlvii).

En De los nombres de Cristo escribe fray Luis que (págs. 561563)

En la orilla contraria de donde Marcello y sus compañeros estavan, en un árbol que en ella avía, estuvo asentada una avezilla de plumas y de figura particular, quasi todo el tiempo que Iuliano dezía, como oyéndole y, a vezes como respondiéndole con su canto, y esto con tanta suavidad y armonía, que Marcello y los demás avían puesto en ella los ojos y los oydos. Pues al punto que Iuliano acabó, y Marcello respondió lo que he referido, y Sabino le quería replicar, sintieron ruydo hazia aquella parte; y, bolviéndose, vieron que lo hazían dos grandes cuervos que, revolando sobre el ave que he dicho y cercándola al derredor, procuravan hazerle daño con las uñas y con los picos. Ella, al 
principio, se defendía con las ramas del árbol, encubriéndose entre las más espesas. Mas cresciendo la porfía, y apretándola siempre más a do quiera que yva, forçada, se dexó caer en el agua, gritando y como pidiendo favor. Los cuervos acudieron también al agua y, bolando sobre la haz del río la perseguían malamente, hasta que a la fin el ave se sumió toda en el agua, sin dexar rastro de sí. Aquí Sabino alçó la voz, y con un grito dijo: - $\mathrm{O}$, la pobre, y cómo se nos ahogó!

Y assí lo creyeron sus compañeros, de que mucho se lastimaron. Los enemigos, como victoriosos, se fueron alegres luego. Mas como uviesse passado un espacio de tiempo, y Iuliano con alguna risa consolasse a Sabino, que maldezía los cuervos y no podía perder la lástima de su páxara, que assí la llamava, de improviso, a la parte adonde Marcello estava y quasi junto a sus pies, la vieron sacar del agua la cabeça, y luego salir del arroyo a la orilla toda fatigada y mojada. Como salió, se puso sobre una rama baxa que estava allí junto, adonde estendió sus alas y las sacudió del agua, y después, batiéndolas con presteza, començó a levantarse por el ayre cantando con una dulçura nueva. Al canto, como llamadas otras muchas aves de su linaje, acudieron a ella de differentes partes del soto. Cercávanla y, como dándole el parabién, le bolavan al derredor. Y luego, juntas todas, y como en señal de triumpho, rodearon tres o quatro vezes el ayre con bueltas alegres, y después se levantaron en alto poco a poco, hasta que se perdieron de vista.

Fue grandíssimo el regozijo y alegría que deste successo recibió Sabino. Mas dezíame que, mirando en este punto a Marcello, le vio demudado en el rostro y turbado algo y metido en gran pensamiento, de que mucho se maravilló. Y queriéndole preguntar qué sentía, viole que, levantando al cielo los ojos, como entre los dientes y con un sospiro dissimulado, dixo:

-Al fin, Iesús es Iesús.

En la alegoría de fray Luis el avecilla representa en primer lugar al propio autor, y los dos cuervos que tan viciosamente la atacan ya no son el "pessimo Manasses e Amon» sino sus dos enemigos principales, fray Bartolomé de Medina y León de Castro. Pero, ¿no podría el avecilla significar también la Biblia, «herida» por sus intérpretes ignorantes pero quedando al fin intacta?

El pasaje citado de la Consolaçam es buen ejemplo de la elegancia de su estilo, que transpone la retórica clásica al portugués del Renacimiento, exactamente como lo haría fray Luis para el 
castellano en De los nombres de Cristo. Y de la misma manera que fray Luis defiende su uso del castellano en la frecuentemente citada introducción al libro III de De los nombres de Cristo, escribe Usque en la introducción a su Consolaçam ${ }^{9}$ :

Algũs señores quiserom dizer antes que soubesen minha razam, que fora milhor auer cõposto em lingoa castelhana, mas eu creo que nisso nam errey, por que sendo o meu principal yntento falar cõ Portugheses o representando a memoria deste nosso desterro buscarlhe por muitos meos e longo rodeo, algum aliuio aos trabalhos que nelle passamos, desconueniente era fugir da lingua que mamey e buscar outra prestada pera falar aos meus naturais: E dado caso que a volta ouue muitos do desterro de Castela, e os meus passados daly ajam sido, mais razao parece que tenha agora conta com o presente e mayor cantidade.

En De los nombres de Cristo fray Luis cita muchas de las mismas profecías bíblicas empleadas por Usque en su Consolaçam. Por ejemplo, en su comentario al nombre «Camino», escribe el siguiente hermoso pasaje sobre el amor eterno de Dios para los judíos, inspirado en Isaías 35:8-10 («avrá allí senda y camino, y será llamado camino santo ... Caminarle han los librados, y los redemidos por el Señor bolverán a andar por él»):

Esto toca propriamente a los del pueblo iudaico, que con el fin de los tiempos se an de reduzir a la Iglesia y, reduzidos, començarán a caminar por este nuestro camino con passos largos, confessándole por Messías. Porque, dice, tornarán a este camino, en el qual anduvieron verdaderamente primero, quando servían a Dios en la fe de su venida que esperavan, y le agradaron; y después se salieron dél, y no lo quisieron conoscer quando lo vieron, y assí agora no andan en él, mas está prophetizado que han de tornar. Y por esso dize que bolverán otra vez al camino los que el Señor redimió. Y tiene cada una destas palabras su particular razón, que demuestra ser assí lo que digo. Porque lo primero, en el original, en lugar de lo que dezimos Señor, está el nombre de Dios proprio ${ }^{10}$, el qual tiene particular significación de una entrañable piedad y misericordia. Y lo segundo, lo que dezimos

9 Las páginas del Prólogo no están numeradas en la edición de Mendes dos Remedios.

${ }^{10}$ I.e., el Tetragramatón, que en el pensamiento cabalístico simbolizaba el atributo de la misericordia, en contraposición al nombre divino Elohim, que simbolizaba el atributo de juicio (Idel pág. 129). 
redemidos, al pie de la letra suena redempciones o rescates ${ }^{11}$; en manera que dize que los rescates o redempciones del Piadosíssimo tornarán a bolver. Y llama rescates o redempciones a los deste linaje, porque no los rescató una sola vez de sus enemigos, sino muchas vezes y en muchas maneras, como las sagradas letras lo dizen.

Sigue diciendo (págs. 217-218):

Y llámase en este particular Misericordiosísimo a sí mismo, lo uno, porque aunque lo es siempre con todos, mas es cosa que admira el estremo de regalo y de amor con que trató Dios a aquel pueblo, desmereciéndolo él; lo otro, porque teniéndolo tan desechado agora y tan apartado de sí, y desechado y apartado con tan justa razón como a infiel y homicida, y pareciendo que no se acuerda ya dél, por aver passado tantos siglos que le dura el enojo, después de tanto olvido y de tan luengo desecho, querer tornarle a su gracia, y de hecho tornarle, señal manifiesta es de que su amor para con él es entrañable y grandíssimo; pues no lo acaban ni las bueltas del tiempo tan largas, ni los enojos tan encendidos, ni las causas dellos tan repetidas y tan justas. Y señal cierta es que tiene en el pecho de Dios muy hondas rayzes aqueste querer, pues cortado, y al parecer seco, torna a brotar con tanta fuerça. De arte que Esaías llama rescates a los iudíos, y a Dios le llama Piadoso, porque sola su no vencida piedad para con ellos, después de tantos rescates de Dios, y de tantas y tan malas pagas dellos, los tornará últimamente a librar y, libres y ayuntados a los demás libertados que están ahora en la Iglesia, los pondrá en el camino della y los guiará derechamente por él.

Usque cita el mismo pasaje de Isaías en un capítulo de su «Diálogo III» titulado «Com en beneficio de ysrael se lhe ha de mudar a natureza a elle e a terra santa» (III, lxiii), donde forma parte de la «Ultima consolação e diuina, com todas las prophecias dos bẽs que ysrael espera por verdadeiro remedio e comprida satisfaçam de todos seus males»: i.e., la profecía de la venida inminente del Mesías para redimir a Israel.

La principal objeción a mi argumento sobre la influencia de la Consolaçam de Usque sobre De los nombres de Cristo será, creo, cómo fray Luis pudo obtener un ejemplar de dicho libro. Ya he mencionado que durante su proceso se le acusó de haber poseído,

${ }^{11}$ I.e., gue 'ulim, que sin embargo, no significa 'redenciones' (gue 'ulot) sino 'los rescatados'. 
sabiendo que era herético, el libro de un italiano que su amigo Benito Arias Montano le había regalado.

En un documento sometido a la Inquisición el 17 de abril de 1572 fray Luis dijo que su amigo el profesor Grajal le había pedido que escribiera a Arias Montano en Flandes, encargándole que le comprara unos libros para Grajal. León afirma no haber conocido los títulos de los libros pedidos, pero añade que Grajal le pidió decirle a Arias: «que sy viese tambien algun otro libro bueno que el supiese que se lo comprase». Parece que fray Luis temía que la Inquisición hubiera interceptado el paquete de libros, que probablemente venía dirigido a él, y dijo que se le había ocurrido «si acaso entre estos libros se señaló algun libro que no fuese bueno ...» (Proceso pág. 58).

Creo que es probable que Arias Montano, bien enterado del interés de fray Luis por todo lo judío, le hubiera enviado antes un ejemplar de la Consolaçam desde Flandes. El libro habría sido fácil de adquirir en los Países Bajos debido a la considerable población judía de habla portuguesa allí asentada. De hecho la segunda edición de la Consolaçam se publicó en Amsterdam en 1599.

Ya he mencionado que muchos críticos modernos, por poco que les hayan interesado las interpretaciones de los nombres de Cristo, han expresado una gran admiración por la retórica del libro, por sus comentarios generales sobre la filosofía del lenguaje y de los nombres, y por su representación de la naturaleza.

El otro aspecto del libro que ha atraído bastante interés entre los lectores del siglo xx ha sido su teoría política. En 1901 señaló Joaquín Costa que «el ideal de fray Luis es una sociedad sin Estado, o más bien un Estado que diríamos, a la moderna, "libertario", en que la gracia divina, alumbrando interiormente las almas, hiciera veces de leyes, y donde el oficio del gobernante fuese como el de pastor» (citado en Castro pág. 282).

Azorín pensaba que lo más interesante de De los nombres de Cristo para el lector moderno son las ideas políticas que contiene: «Pero en este libro encontramos algo que es episódico, marginal, y que, sin embargo, hoy para nosotros es lo que constituye su esencia» (pág. 184), y afirma que «en este terreno nos hallaremos perfectamente de acuerdo con nuestro autor» (pág. 186). Según Azorín, «lo fundamental para el poeta es la separación entre la justicia y la ley; a la par de esta idea, fray Luis expone la concepción polí- 
tica de que no se podrá hacer nada bruscamente, por una ley, si lo que se dispone no está ya en el ambiente» (págs. 186-187).

Américo Castro fue el primero en ver una conexión entre la teoría política de fray Luis y su condición de converso. «Luis de León», escribe, «no trata de esta cuestión sólo por motivos teóricos y de 'Cristolatría'; el tema de la ley y de la justicia tiene aquí ${ }^{12}$ una dimensión vital, autobiográfica, y adquiere sentido al coordinarlo con otros lugares de los Nombres de Cristo» (pág. 283). Llama la atención particularmente sobre un pasaje del diálogo sobre el nombre «Rey de Dios» donde fray Luis señala que, a diferencia de Cristo, los reyes de hoy, por no haber experimentado la aflicción y la pobreza, agobian a sus sujetos con yugos pesados y leyes estrictas, que luego aplican con crueldad y rigor.

Escribe Castro que: «el cerco de la angustia se va estrechando, y va apareciendo lo que en verdad motiva hablar de la ley y de lo justo: ¿cómo han de ser "las condiciones de los que en este reino son súbditos? Y, a la verdad, casi todas ellas se reducen a ésta, que es ser generosos y nobles todos, y de un mismo linaje"». Concluye: «He ahí el problema, la dolida llaga que hace clamar a muchos españoles de primera clase, en 1583 ...» (pág. 283). A continuación cita Castro un largo pasaje del mismo diálogo en que fray Luis insiste en que la nobleza del reino de Cristo está basada en el hecho de que en él «ningún vasallo es ni vil en linaje, ni afrentado por condición, ni menos bien nacido el uno que el otro. Y paréceme a mí que esto es ser rey propia y honradamente, no tener vasallos viles y afrentados» (pág. 283). Un reino que discrimina contra muchos de sus sujetos, «adonde muchas órdenes y suertes de hombres y muchas casas particulares están como sentidas y heridas, y adonde la diferencia, que por estas causas pone la fortuna y LAS LEYES, no permite que se mezclen y se concierten bien unas con otras, está sujeto a enfermar y a venir a las armas con cualquiera razón que se ofrece. Que la propia lástima e injuria de cada uno encerrada en su pecho, y que vive en él, los despierta y los hace velar siempre a la ocasión y a la venganza» (pág. 284).

Que yo sepa, ningún otro autor de la época se atrevió a sugerir que la discriminación continuada contra los cristianos nuevos conduciría inevitablemente a la insurrección armada.

\footnotetext{
12 Por ejemplo, en los comentarios de fray Luis sobre el nombre «Pastor», arguye que el gobierno de Cristo no consiste en leyes escritas iguales para todos, sino que toma en consideración las circunstancias de cada individuo gobernado.
} 
Aunque Castro escogió algunos de los pasajes más sobresalientes, tales sentimientos ocurren constantemente a lo largo de De los nombres de Cristo. Por ejemplo, en el primer nombre que comenta («Pimpollo»), trae a colación fray Luis la cita de Gálatas 3:27-28 («Todos los que en Cristo os habéis bautizado, os habéis vestido de Jesucristo; que allí no hay judío ni gentil, ni libre ni esclavo, ni hembra ni varón, porque todos sois uno en Jesucristo»), el pasaje del Nuevo Testamento que más explícitamente condena la discriminación contra los hermanos en Cristo por motivos étnicos, estado social o género.

Hay muchos pasajes en De los nombres de Cristo que tratan más o menos sutilmente la cuestión de la discriminación por limpieza de sangre. Sólo voy a citar uno, que me parece el más asombroso de todos. Comentando el nombre «Cordero», escribe fray Luis que (págs. 576-577):

... cosa fuera de toda duda es que el cuerpo de Christo, de su misma cosecha, era de inclinaciones excellentes, y en todas ellas fue loable, honesto, hermoso y excellente. Que se convence, ansí de la materia de que se compuso, como del artífice que le fabricó. Porque la materia fue la misma pureza de la sangre sanctíssima de la Virgen, criada y encerrada en sus limpias entrañas. De la qual avemos de entender que, aun en ley de sangre, fue la más apurada y la más delgada y más limpia, y más apta para crialla, y más agena de todo affecto bruto, y de más buenas calidades de todas, porque, allende de lo que la alma puede obrar y obra en los humores del cuerpo, que, sin duda, los altera y califica según sus affectos, y que, por esta parte, el alma sanctíssima de la Virgen hazía sanctidad en su sangre, y sus inclinaciones celestiales della, y los bienes del cielo sin cuento que en sí tenía la espiritualizavan y sanctificavan en una cierta manera, ansí que, allende desto, de suyo era la flor de la sangre, quiero dezir, la sangre más agena de las condiciones grosseras del cuerpo, y más adelgazada en pureza que en género de sangre, después de la de su Hijo, jamás uvo en la tierra. Porque se ha de entender que todas las sanctificaciones y purificaciones y limpiezas de la ley de Moysén -el comer estos manjares y no aquéllos, los lavatorios, los ayunos, el tener cuenta en los días-, todo se ordenó para que, adelgazando y desnudando de sus affectos brutos la sangre y los cuerpos, y de unos en otros apurándose siempre más, como en el arte del distillar acontece, viniesse últimamente una donzella a 
hazer una sangre virginal por extremo limpíssima, que fuesse materia del cuerpo puríssimo sobre todo estremo de Christo. Y todo aquel artificio viejo y antiguo fue como un distillatorio que, de un liquor puro sacando otro más puro por medio de fuego y vasos differentes, llegue a la sutileza y pureza postrera.

Este pasaje me parece realmente extraordinario. En primer lugar, ya que María era judía, si su sangre era «la misma pureza» y «la sangre más limpia», ¿cómo podía el tener sangre judía ensuciar a nadie? Pero en caso de que el lector hubiera pasado por alto un punto tan importante -y sabemos de sobra que los españoles del Siglo de Oro estaban acostumbrados a hacer caso omiso del judaísmo de María y de Jesús- explica fray Luis que el guardar las reglas del kašerut, el sumergirse en la micvé, los ayunos, el abstenerse de las relaciones sexuales durante y después de la menstruación («el tener cuenta en los días»), etc., durante un período de muchos siglos obraron una suerte de transformación genética en la sangre judía, convirtiéndola en limpíssima y digna de formar el cuerpo puro de Jesucristo. Si esto era verdad en la época de Jesucristo, ¿cuánto más lo sería para los judíos de la época de fray Luis, que habían seguido practicando los mismos ritos durante tantos siglos?

Exactamente como lo había hecho Usque en su Consolaçam, fray Luis concluye De los nombres de Cristo con una ardiente expresión de confianza en la inminente llegada de la época mesiánica, en que por fin terminarían el sufrimiento y la opresión de los judíos y de los cristianos nuevos, y triunfarían la justicia, la paz y el amor (pág. 655):

Dios, a la fin, es deshacedor de agravios y gran hazedor de justicias. Siempre se compadece de los que son saqueados y les da su derecho; que si tú no merecías merced, el engaño con que tu ponçoñoso enemigo te robó tus riquezas, bozeava delante dél por remedio. Desde que lo vio se determinó remediarlo, y les manifestó a Moysén y a los hijos de su amado Israel su consejo, el ingenio de su condición, su voluntad y su pecho, y les dixo: Soy compassivo y clemente, de entrañas amorosas y pías, largo en suffrir, copioso en perdonar, no me acelera el enojo, antes el hazer bienes y misericordias me acucia; passo con ancho coraçón mis offensas, no me doy a manos en el derramar mis perdones, que no es de mí el enojarme contino, ni el barajar siempre con vosotros no me puede aplazer. 
De hecho, Usque y fray Luis terminan sus libros con una paráfrasis de un salmo. Usque escoge el salmo 126, que describe la vuelta triunfante de los exiliados a Sión. Las estrofas finales rezan (lxxviiii):
Quando nosso Señor restetuir
a Ziom, a sua antigua gloria cuidaremos q̃ o ben nam he de siso
e que estamos sonhando entre dia ...
E sem duuida fara nosso Señor
restauração ao nosso catiueiro
como elle rega o aruore em secura
e os que vam cõ lagrimas semeãdo
Com prazer segaram por derradeiro
choroso vay o bom semeador
Mas elle tornara doutra figura
trazendo molhos e feixes e cantando.

Fray Luis parafrasea el salmo 98 (97 en la Vulgata), escribiendo en parte lo siguiente (págs. 657-658):

Él mismo de la huessa, a la luz bella

Restituyó tu vida;

Cercóla con su amor, y puso en ella

Riqueza no creyda.

Y en esso que te viste y te rodea

También pone riqueza;

Ansí renovarás lo que te afea,

Qual águila en belleza.

Que al fin hizo justicia y dio derecho

Al pobre saqueado;

Tal es su condición, su estilo y hecho,

Según lo ha revelado.

Me parece probable que al escoger el nombre de Marcelo para el personaje principal de sus diálogos De los nombres de Cristo estaba pensando fray Luis en el Marcelo celebrado por su querido Horacio en la Oda I.12. Símbolo de la pax romana, Marcelo encarnaba a la vez la potencia militar de Roma y su gobierno justo e imparcial de los pueblos sometidos. La oda de Horacio concluye: 
Te minor latum reget aequus orbem;

Tu gravi curri quaties Olympum,

Tu parum castis inimica mittes

Fulmina lucis ${ }^{13}$.

Según las famosas palabras de la Eneida, el destino de Roma era «pacisque imponere morem, / parcere subiectis et debellare superbos» ('acostumbrar a los hombres a vivir en paz, mostrarse generosa con los sujetos y firme contra los agresores'). En De los nombres de Cristo fray Luis aboga por una nueva pax romana, esta vez fomentada por la iglesia, sucesora del Imperio.

Si mis estudiantes odiaban las absurdas interpretaciones alegóricas de los nombres de Cristo, era porque así lo quería fray Luis. Seguimos leyendo el Quijote con gusto y provecho a pesar de que su parodia de los libros de caballerías ya no tiene vigencia. Lo mismo puede pasar con De los nombres de Cristo si nos damos cuenta de que su verdadera originalidad e importancia estriban en su valiente denuncia de la injusticia de despreciar y perseguir a nuestros prójimos a causa de su ascendencia. Igual que el Quijote, De los nombres de Cristo nos recuerda sobre todo que «cada uno es hijo de sus obras».

\section{BIBLIOGRAFÍA}

AlCAlÁ, Ángel, «De la datación e importancia del Tractatus de Sensibus Sacrae Scripturae de fray Luis de León», Revista Agustiniana 32 (1991) págs. 859-882.

- «Peculiaridad de las acusaciones a fray Luis en el marco del proceso a sus colegas salmantinos", vid. Fray Luis de León: Historia, humanismo y letras págs. 65-80.

CAstro, Américo, La realidad histórica de España (3a ed., México: Porrúa, 1966).

Cervantes SaAvedra, Miguel de, El ingenioso hidalgo don Quijote de la Mancha, ed. Luis Andrés Murillo, 2 vols. (Madrid: Clásicos Castalia, 1978).

Durán, Manuel, Fray Luis de León (Nueva York: Twayne Publishers, 1971).

Ezrá de Gerona, Le Commentaire d'Ezra de Gérona sur le Cantique des Cantiques, ed. y trad. Georges Vajda (París: Aubier Montagne, 1969).

13 'Bajo ti, la justicia [de César] reinará sobre el ancho globo; / sacudes a Olimpo con tu grave carro, / fulminarás con tus castos rayos / las sagradas arboledas profanadas por la iniquidad'. 
FERnÁndez Marcos, Natalio, "De los nombres de Cristo de fray Luis de León y De arcano sermone de Arias Montano», en Biblia y humanismo, eds. Natalio Fernández Marcos y Emilia Fernández Tejero (Madrid: Fundación Universitaria Española, 1997) págs. 133-152.

Fray Luis de León: Historia, humanismo y letras, eds. Víctor García de la Concha y Javier San José Lera (Salamanca: Ediciones Universidad de Salamanca, 1996).

GARCÍA DE LA FuenTE, P. Olegario, «Un tratado inédito y desconocido de Fray Luis de León sobre los sentidos de la Sagrada Escritura», La Ciudad de Dios 70 (1957) págs. 259-334.

IDEL, Moshe, Kabbalah: New Perspectives (New Haven: Yale Univ. Press, 1988).

LEón, Luis de, Exposición del Cantar de los Cantares de Salomón, en Obras completas castellanas de fray Luis de León, ed. Félix García (4a ed., Madrid: Biblioteca de Autores Cristianos, 1957) 2 vols.

- De los nombres de Cristo, ed. Cristóbal Cuevas García (5a ed. Madrid: Cátedra, 1986).

MARTÍNEz Ruiz, José, Los dos Luises y otros ensayos [1 ${ }^{\text {a }}$ ed. 1921], en Obras completas, ed. Ángel Cruz Rueda (Madrid: Aguilar, 1961) vol. IV págs. 141-213.

Morón Arroyo, Ciriaco, «Espesor de la letra: La hermenéutica de fray Luis de León», vid. Fray Luis de León: Historia, humanismo y letras págs. 299-312.

Nieto IbÁÑEZ, Jesús María, "San Macario de Egipto traducido en De los nombres de Cristo de fray Luis de León», La Ciudad de Dios 211 (1977) págs. 553-571.

Proceso inquisitorial de fray Luis de León, ed. Ángel Alcalá (Salamanca: Junta de Castilla y León, 1991).

RAllo GRUSS, Asunción, «El diálogo como exégesis: función filológica y función catequística en De los nombres de Cristo», vid. Fray Luis de León: Historia, humanismo y letras págs. 451-469.

Thompson, Colin P., La lucha de las lenguas: Fray Luis de León y el Siglo de Oro en España, trad. María Isabel Sáinz-Ezquerra (Salamanca: Junta de Castilla y León, 1995).

Usque, Samuel, Consolaçam ás Tribulaçoens de Israel, ed. J. Mendes dos Remedios (Coimbra: França Amado, 1906).

Vossler, Carlos, Fray Luis de León (3a ed., Colección Austral 565, Madrid: Espasa-Calpe, 1965). 


\section{RESUMEN}

Es sumamente curioso que De los nombres de Cristo sea el único de los comentarios bíblicos de fray Luis de León en el que se valió de las interpretaciones tipológicas o alegóricas. Fue sobre todo su insistencia en la prioridad del sentido literal del texto hebreo de la Biblia lo que llevó a su detención por la Inquisición en 1572. En este artículo propongo que De los nombres de Cristo, comenzado en la cárcel, es más que nada su autodefensa contra las acusaciones de sus enemigos. Los temas principales del libro no son los nombres de Cristo sino (1) el sentido de la historia y (2) la justicia y el ejercicio lícito del poder. Sugiero que, para el desarrollo de estos dos temas, fray Luis se inspiró en el libro Consolaçam ás tribulaçoens de Israel (1533) de Samuel Usque.

\section{SUMMARY}

It is extremely interesting that De los nombres de Cristo is the only one of Fray Luis de León's biblical commentaries in which he made extensive use of allegorical interpretation. It was above all his insistence on the priority of the literal meaning of the Hebrew text of the Bible that led to his arrest by the Inquisition in 1572. In this article I propose that De los nombres de Cristo, which Fray Luis began writing in jail, was above all his self-defense against the charges brought against him by his enemies. The book's principal theme is in fact not the names of Christ but (1) the meaning of history, and (2) justice and the proper exercise of power. I suggest that Fray Luis's development of these themes was inspired by his reading of Samuel Usque's Consolaçam ás tribulaçoens de Israel (1533). 